\title{
THE ECONOMICS OF EARTHQUAKE ENGINEERING
}

\author{
J. P. |Hollings*
}

\section{Synopis}

This paper attempts to provide the designer of large scale engineering works with a rational method for judging how much capital it is proper to spend on earthquake engineering for the project in question. It does this by setting up the concept of a hypothetical disaster fund maintained by capital contributions from each new project built.

A variety of examples is given to illustrate the argument and the application of the method.

\section{$1.0 \quad$ Introduction:}

Engineers have the responsibility for planning the investment of large sums of capital in physical works of all kinds。

As part of this planning, in seismically active areas they also have the responsibility for deciding how much additional capital should be spent in providing a measure of earthquake resistance for the project. This additional sum of capital, over and above that needed for the same scheme in a non-seismic area, can be defined as the cost of earthquake engineering.

Although there has been some discussion (e.g. Reference 1) in the technical press on the cost of earthquake engineering, there has been no discussion anywhere, to the writer's knowledge, on how high this cost should be allowed to rise for any particular project: that is, what level of expenditure should properly be committed for earthquake engineering. In current practice an appropriate expenditure is set, partly automatically by conventional rules such as codes, but equally as much by the judgement of the particular design engineer or earthquake "expert". Experts are notoriously narrow and biased and earthquake engineering experts are no exception: that is, they tend to indulge their specialty to the exclusion of wider problems. In the context of this paper this means that excessive sums may be arbitrarily allocated as appropriate expenditures for earthquake engineering a particular project.

The purpose of this paper is to outline objective criteria or guidelines for assessing an appropriate earthquake engineering expenditure and, through examples, to compare the results obtained by applying these criteria with the current practice of earthquake engineering.

The principle of this approach is not limited to any one branch of engineering but is general and is meant to be applied to any

* Consulting Engineer, Beca, Carter, Hollings

\& Ferner, Wellington. engineering project of whatever type for which earthquake resistant measures are necessary.

The guidelines proposed are not intended for application individually to each and every small project: thousands of these are designed each year and for the moment it is assumed the local codes are sufficient guidelines for these works (a1though perhaps the codes themselves could be re-examined using the techniques of this paper). Instead, the criteria outlined are intended to be applied to those few large works where the sums allocated as appropriate expenditures for earthquake engineering are themselves large and warrant some refinement.

It is recognised that because of the many uncertainties involved, these guidelines must be far from precise: however, it must also be recognised that "the art of the engineer lies in getting a solution to a problem for which there is not enough information". (Reference 2). The economics of earthquake engineering is such a problem and in this paper wherever a doubtful variable occurs, high upper limits have in every case been selected. This leads to the generally excessively conservative results of this paper. Engineers dealing with a particular problem may choose to exercise their "art" and use more moderate values.

\subsection{Public and Private Investment:}

Before developing the main argument of this paper it is necessary to deal with the special case of the private investor. For the purpose of this paper, the private investor is defined as one who cannot afford to risk the loss he might sustain in a large earthquake and who, therefore, must insure against this risk. The public or state investor is one who carries his own risk. (Some very large companies might of course also choose to do this).

Quite apart from the private investor's need to insure in order to protect himself against a loss which might bankrupt him, it can also be shown that for the private investor earthquake protection obtained by means of insurance - the cost of which is spread over future years - will always be less costly than earthquake protection obtained by engineering measures, the cost of which is borne at the time of construction.

This can be best illustrated by an example in which the two types of expenditure are compared. In order to make a comparison it is necessary to convert both types to the same basis. Throughout this paper this is done by converting the future annual payments to an equivalent present capital sum for comparison with the proposed capital sum for expenditure on 
206

earthquake engineering. This is known as the "present value" method which determines an equivalent present day capital sum which if invested at the time of construction at a specified rate of interest (to be selected according to circumstances) will create a fund from which annual payments can be made exhaust ing the fund at the end of the required term.

Thus, to return to the example, take the worst earthquake risk recognised by insurance companies: this is a brick structure on filled or reclaimed ground, for which the premium is $0.5 \%$ of the insured value per annum, or 0.00 $X$ dollars for a building insured for $X$ dollars. Assuming for the purpose of this example that the company's earning rate is $15 \%$ before tax then, for a structure with a 30 year life, the premiums paid during that period have a present value of:

$0.005 X+0.005 x / 1.15+0.005 x / 1.15^{2} \ldots$ to 30

terms

(this assumes the first payment of $0.005 \mathrm{X}$ is paid at the beginning of the first year after construction is complete)

$=7.61 \times 0.005 \mathrm{X}$

\section{$=0.038 \times$ dollars.}

Thus, this calculation shows that if $X$ is taken to be the capital cost of the building at the time of construction, then $3.8 \%$ of $\mathrm{X}$, if invested in the company at a rate of return of $15 \%$, would cover the necessary premiums.

A sum of similar order is obtained (the exact amount depending on circumstances) if loss of profits insurance is taken out for earthquake. Insurance against loss of life in earthquake is not normally required of a building owner (viewing the matter solely from a commercial angle) since, if the normal bylaws are complied with, a claim cannot be substant iated against him. Thus, for a total sum of the order of $6 \%$ or $7 \%$ of initial cost, a private investor can obtain complete protection against a11 earthquake loss. In contrast the same sum if invested in earthquake provisions (as is shown later in specific examples) can be expected to provide only partial protection. There will nearly always be some damage despite the engineering precautions taken.

Some comment on the assumptions of the above argument is appropriate.

(i) The company's earning rate before tax is taken since insurance premiums are a deductible expense.

(ii) If the company's earning rate is more than $15 \%$ the capitalised cost of insurance will be less than that above.

(iii) It will also be less if depreciation is allowed for since the future premiums will be paid on a smaller capital value.

(iv) It will be less for almost any other type of building than that allowed in the example.

(v) It will be much less if the insurance is placed with the N.Z. Earthquake and War Damage Commission.

(vi) It is hardly affected if the building's 1 ife is doubled to 60 years since the present value of the premiums then increases from $3.8 \%$ to only $3.81 \%$. (vii) Inflation is not a factor since although it will increase the amount of the future premiums, it will also increase the money value of the company's earnings to compensate.

Thus it may be concluded that for the private investor for whom earthquake insurance is available on the current market such insurance should be carried to ensure economic survival in the event of a major earthquake as it will generally be much cheaper than engineering measures for earthquake protection.

For the state (or very large private investor) the problem is different: thus the state does not insure because:-

(i) It can absorb the loss from any one event however large.

(ii) It would not be possible to insure the State's assets with insurance companies because none would be prepared to accept the large sums placed at risk.

(iii) In the long run it is cheaper for the state to carry its own risk rather than pay an insurance company to do so.

In what follows the argument deals with the State or public investor as defined above. This is not because this paper aims to solve the problems of state investment: it is only because in this way the problem can be treated generally and the argument developed, then applied to any large project of whatever type.

\subsection{Alternatives to Spending Capital Sums on Earthquake Engineering}

To decide how much to spend on earthquake engineering for a particular project we need an equally satisfactory alternative.

To properly achieve the aim of this paper we should seek the lowest cost alternative. Space permits the examination of only two: the alternative chosen may be more costly than other alternatives not yet thought of, but it will be sufficient here as an upper bound.

The two alternatives are :-

(i) Borrow overseas at the time of a disaster a sufficient sum to pay all costs.

or (ii) Maintain a disaster fund invested in overseas* securities and of sufficient size at any time to pay all costs from a specific disaster.

As a first step it is necessary to evaluate the annual cost of each of these proposals (i.e. the annual cost of future earthquakes): later this annual cost, which varies for different projects, must be converted to a capital sum

* Although some of this fund might be invested internally, it is important that it should be in assets which can be readily liquefied in the event of a disaster: thus, investment in power stations, motorways or harbour works would be unsuitable. On the other hand, readily available overseas cash could be used for the prompt import of materials, plant, and, if necessary, labour to repair the damage while still maintaining $N$. Z." S current level of production of goods and services and thus her current standard of Iiving. 
(the present capital cost of future earthquakes) for comparison with the proposed investment in or cost of earthquake engineering for the project.

\subsection{The Annual Cost of Future Earthquakes}

To discuss this it is first necessary to select a "return period" for the "disaster" earthquake here defined as an intensity of shaking $1 \frac{1}{2}$ times as severe as the El Centro record and inflicted on every structure in New Zealand on average once every 50 years. This quite grossly conservative assumption has been selected to ensure the results of this analysis remain clearly an upper bound in spite of the lack of knowledge of earthquake frequency.

Refer now to Figure 1. An interest rate of $6 \%$ has been selected as reasonable for each of the suggested alternatives.

The Iine ABCDE etc. shows how a uniform payment of one dollar per annum into a fund accumulates at a compound interest rate of $6 \%$ per annum. Withdrawals of the whole sum at 50 year intervals to correspond with a 50 year disaster return period are shown. The graph shows that one dollar per annum accumulates to \$290* at the end of each 50 year period and represents diagrammatically the behaviour of a disaster fund (para.3.0 (ii) ) with perfectly equally spaced earthquakes.

The line $A^{\prime} C^{\prime} C^{\prime} E E^{\prime}$ etc. shows the effect of borrowing the $\$ 290$ at equal intervals of 50 years and of making annual equal repayments so that the borrowed sum is fully paid of $f$ each 50 years. (Alternative (ii) of para. 3.0). Compound interest calculations show that for this scheme the annual payments required for the $\$ 290$ capital sum are $\$ 18.4$ compared with the $\$ 1$ per annum of the previous scheme. Thus, it is concluded that the disaster fund concept (Alternative (i) of para. 3.0) should be selected for further study.

Referring again to Figure 1 we see that if the accumulated fund, instead of being withdrawn at the end of the 50 year period, is allowed to further accumulate, the rate of increase becomes much steeper so that after only 80 years four disaster type earthquakes (FG plus HJ) can be dealt with without exhausting the fund. (Line BFGHJ). Conversely, should such an earthquake occur after on 1 y 30 years it may be necessary to borrow with consequent high repayments in order to maintain the fund. To deal with this effect the curve AN has been adopted as reasonable having regard to the very conservative assumptions already made. This curve produces the required 50 year sum in 28 years.**

Compound interest calculations show that the curve AN represents an annual payment of 1. $5 \%$ of the capital sum involved.

In summary then, the argument so far purports to say that if $1 \frac{1}{2} \%$ of all the capital

* This graph and the figures quoted from it assume that the first payment into the fund is made at the end of the first year after the fund begins. If instead the first payment is made at the beginning of the first year, the $\$ 290$ becomes $\$ 308$ with simllar minor changes to the other figures quoted.

* 27 years if the first payment into the fund is made at the beginning of the first year. represented by permanent works in New Zealand 207 was each year invested in a fund bearing $6 \%$ interest, such a fund could be expected to provide for a total write-off of this capital sum from earthquakes with a return period of 50 years.

of course total destruction from earthquake does not occur in cities and towns of western nations, even when the structures of these are not specifically designed for earthquake. The proportion of damage to the total capital investment at risk is called the loss ratio. The evaluation of this is another indefinite variable. Factual information is rare, however a useful guide is given in J。 Freeman's well known text. (Reference 3). Freeman gives loss ratios for various types of buildings, ground conditions, etc. His averaged overall loss ratio allows a spot check of the argument so far against present insurance rates. For an area as large as New Zealand, Freeman suggests that a loss ratio of $5 \%$ will be very conservative averaged over all. Applying this to the $1 \frac{1}{2} \%$ annual sum computed above gives the figure of $0.075 \%$ per annum for the overall total risk in New Zealand, which compares reasonably with the $0.05 \%$ charged by the New Zealand Earthquake and War Damage Commission.

\subsection{The Present Capital Cost of Future Earthquakes:}

Since in studying any particular project it is the capital investment which is being considered, it is necessary to convert the $1 \frac{1}{2} \%$ per annum to an equivalent capital sum for comparison.

This capital sum varies for the number of years for which the annual payment must run (i.e. the life of the project). It also varies with the interest rate which has been fixed here at 6\%。 (Appropriate as described above for the current return on investment in securites outside N.Z.).

In addition it is necessary to allow for varying degrees of loss in the disaster area of a major earthquake. This loss ratio will be different for varying projects.

The necessary compound interest calculations for varying loss ratios and for varying project lives result in the graphs of Figs. 2 and $3 *$. (As in the example of paragraph 2。0 these curves do not allow for depreciation and are therefore slightly conservative: again, inflation is not a factor), since the value of

* As for Figure 1 these graphs have been calculated assuming the first of the annual payments occurs at the end of the first year. If it is desired that the first payment should occur at the beginning of the first year there will be a slight upward adjustment of the equivalent initial capital required amounting to about $10 \%$ for short 1 ife and $5 \%$ for long life projects. As will be seen in the examples given later these adjustments hardly affect the accuracy of the final answers obtained when the many assumptions necessary are taken into account.

Note that the graphs of Fig. 3 refer to loss ratios in excess of $100 \%$. This is to take account of consequential losses such as life and loss of income as will be explained later. 
208

overseas investments made by the fund will be subject to similar inflationary trends as the risk insured.

As an example of the curve's application reading from Figure 2., a project with a proposed to year 1 ife and stimated to have a loss ratio of $10 \%$ within the disaster area of a disaster type earthquake requires a capital contribution to the fund of $2.2 \%$. That is, $2.2 \%$ of the capital value of the project if invested in the earthquake fund will provide complete cover for the structure throughout its 1iIe. It is this sum which must be compared with the sums spent on earthquake engineering in an attempt to provide partial protection for the project.

Before applying these graphs to specific examples jt is necessary to discuss in a general way the amount and kind of protection which can be hopefully provided for a structure through earthquake engineering.

\subsection{The Objectives of Earthquakes Engineering:}

It is taken as axiomatic that the objectives of the engineer designing for earthquake can be met if he achieves at least in part:-

(i) Reduction of damage (both structural and non-structural

(ii) Reduction of the loss of 1 ife.

(iii) Reduction of the risk of the structure going out of service.

For different projects these objectives will have widely differing degrees of importance.

Thus, the exercise of deciding how much capital should be spent on earthquake engineering for a project must be sub-divided into these three categories and the decision made for each in turn。

Before this can be done it is necessary to try to isolate those factors which control damage, those which control the loss of 1 ife, and those which control the project's ability to remain in service.

\subsection{Measures to control damage:}

If a structure can be made strong enough to remain purely elastic during the passage of a major shaking it will not sustain any damage. Figure 4. indicates the order of structural strength required to achieve this and shows that, because the margin between code loads and elastic response is so great :-

(i) There must be structural damage as energy is absorbed in the post-elastic phase of structural response.

(ii) There must be substantial deformations as energy is absorbed and therefore substantial secondary damage (unless large clearances are provided for nonstructural elements).

(iii) Increases in strength of up to a hundred per cent are likely to have little effect in damage reduction - several hundred per cent are necessary.

It is concluded therefore that :-

-. Structural damage especially and to a smaller degree non-structural damage is influenced mainly by STRENGTH.
... Further, that while it is possible to reduce damage by increasing strength, full elastic strength must be provided to eliminate structural damage completely and some non-structural damage may still occur.

6.2 Measures to control loss of 1 ife and the risk of the structure going out of service:

Similar precautions are needed for cach of these and here it is not the elastic strength which provides for life and serviceability but rather the integrity designed into the structure for the post-elastic phase of its response to the shaking. This agin is because of the wide gap between code strength and elastic response. Again, very substantial strength increases are needed to effectively alter this situation. Without these increases attention should be concentrated on the post-elastic performance commonly referred to as the ductility of the structure: or more directly described perhaps as the ability of -

(i) Vertical load carrying members to continue to carry vertical load.

(ii) The structure to not separate into its component parts. (Beams remain on columns, unit masonry stays together, etc.)

\subsection{IIIustrative Examples:}

The following examples show how the methods described in the preceding paragraphs might be applied in practice to projects in which the three objectives of earthquake engineering have widely differing importance. The examples are drawn at random from the author's practice and elsewhere and, in each case, the project design was completed before this analysis was carried out. Thus, the results in some cases show the sums spent on earthquake eingineering to be reasonable, in some cases perhaps more than was justified. It will be noted again that there is great scope for judgement in choosing the appropriate value for the variables concerned but that again each time a conservative upper bound has been selected. With more care and research more appropriate figures could be found for major works and the results thus refined. Some of the examples given would not usually be regarded as of sufficient importance to warrant an analysis (e.g. some of the buildings which are in any case controlled by the N.Z. Bylaw Code) but they have been included because the inform. ation was readily available to illustrate the method.

\subsection{A Warehouse Building:}

This example (chosen for its simplicity and shown in Fig. 5) is a storage building with precast concrete columns, steel and timber roof framing, concrete block walls and of approximate area $120,000 \mathrm{sq}$. ft.

Under the headings of the three objectives it is found that :-

(i) The cost of the loss of life is negligible since nobody works in it or around it.

(ii) The cost of going out of service is very small since, although the build. ing might be damaged enough to let water in, temporary protection for 
the contents can easily be obtained with tarpaulins. (It is assumed that due to the precautions mentioned below, actual collapse will not occur.)

With these assumptions the sole consideration is the cost of damage.

The loss factor for buildings of this type must first be estimated. That is, what percent age of total capital invested in this type of building in the whole of the disaster area is lost on each shaking. It is a basic assumption that no precautions are taken to resist earthquake but that good building practice is otherwise followed. Freeman (Reference 3) suggests a 1 oss factor of $5 \%$ for well constructed brick buildings of warehouse type up to 3 storeys high and $10 \%$ on bad ground. This one is on a crust of good fill over marine sediments - so take $10 \%$ as conservative. Using a design life of 30 years, the graph of Figure 2. shows that $2 \%$ of initial capital cost is the absolute maximum which can be justified for damage protection alone. That is, this sum invested in the fund will totally cover all earthquake damage for the 30 year design 1 ife.

An analysis of the building shows that at least $4 \frac{1}{2} \%$ of initial capital cost was spent in order to provide for code base shears (this is over and above wind, which was not dominant for this building because of its large plan area and low height).

As explained in paragraph 6.1, the level selected for base shear primarily controls the damage level, although for a low building such as this one, it also contributes significantly to safety.

It might be mentioned in passing that because of the possibility of a change in use during the building's life (to manufacturing for example) with a consequent risk to the life of perhaps many people, it was decided, as a professional'responsibility, that certain direct measures should be taken for life protection. These are in the category described in paragraph 6.2 and are over and above the code requirements. They consist mainly of through tying of the roof structure in both directions (and tying to the columns and block walls) up to the full value determined from plastic hinge moments in the columns. The columns themselves were also designed to sustain these plastic hinge rotations. The routine of these techniques is fully described in Reference 4.

These measures provide a high degree of safety for the main structural elements of this building in a major shaking for an estimated cost of $1.5 \%$ of initial capital cost. Notwithstanding this extravagance, the building turned out to be extremely economical.

\subsection{A High Rise Apartment Building:}

This example has been chosen because of its high potential risk to life.

It is a reinforced concrete structure (refer Figure 6.) of 16 storeys with flat plate floors of approximately 5,000 sq.ft. each. All of the lateral force or earthquake resistance is concentrated in reinforced concrete frames placed in the planes of the exterior walls.

Again it is first necessary to estimate a
209

loss factor for buildings of this type。 Referr ing again to Freeman - a well built reinforced concrete structure on rock (as this one is) but without special precautions for earthquake may be expected to have a loss ratio of $3 \%$ (taken over the disaster area only). This figure includes all damage and actual collapse is quoted as rare.

It is judged therefore that to take $1 \%$ of the se buildings in the disaster area as total collapses will be conservative.

The three objectives of earthquake engineering may now be evaluated separately.

\section{(i) Protection of Life:}

To assess the cost of life loss, assume the total building population of 300 to be resident at the time of collapse and to be lost as a result of the collapse and take the value of one human 1 ife as $\$ 100,000 *$. The actual financial loss per building due to the loss of human life is then $300 \times 1 \% \times 100,00$, i。e. $\$ 300,000$.

The total value of the building is approximately $\$ 1,500,000$ so the loss ratio for 1 ife alone is $20 \%$. If this is now applied to Figure 2 assuming a 40 year 1 ife, then $4 \frac{1}{2} \%$ is obtained as the equivalent capital sum which, if invested in the disaster fund, will totally cover all life loss for the 40 year structure life。

Referring now to the structure itself those measures wholly and solely directed to the prevention of collapse and thus the reduction of life loss consist of attempts to improve the post-elastic performance of the structure. (Refer para 6.2) These consist of special binding and shear steel in beams and especially in columns (refer Figure 7) and special structural steel slab reinforcing (refer Figure 8 and Reference 5). For this structure the total cost of these provision has been estimated at $\$ 21,000$ or $1.4 \%$ of total building cost $(\$ 1,500,000)$. In comparing this $1.4 \%$ with the $4 \frac{1}{2} \%$ estimated above it must be remembered that code or strength requirements also contribute to life protection.

\section{(ii) Reduction of Damage:}

Now to assess the cost of damage protection and using again Freeman's loss ratio of $3 \%$, Figure 2 gives for a 40 year 1 ife $0.7 \%$ as the sum which invested in the fund will give complete cover against a11 damage during the 40 year structure life. To assess the amount actually spent on damage protection, the graphs of reference 1. are useful. The relevant graph is reproduced here as Figure 9. For this building the design base shear was 0.1 and the wind base shear was 0.03 . Thus, from Figure 9 for $(0.1-0.03), 18 \%$ of structural cost can be read as the total cost of seismic base shear

* The actual sum which should be chosen here is open to a wide range of opinion - clearly there will be some projects for which a higher value would be prudent in a calculation of this type. However, in every case a finite figure must be selected if an assessment of economic loss is to have meaning. A general discussion of some of the factors involved will be found in Reference 6, Page 137. 


\begin{tabular}{|c|c|c|c|}
\hline & $\begin{array}{l}\text { For direct life pro- } \\
\text { tection (extra bind- } \\
\text { ing and shear rein- } \\
\text { forcement - structural } \\
\text { steel in slabs around } \\
\text { columns) }\end{array}$ & $\begin{array}{l}\text { For direct damage } \\
\text { protection and } \\
\text { indirectly to assist } \\
\text { in life protection }\end{array}$ & Total \\
\hline $\begin{array}{l}\text { The sum actually } \\
\text { spent on engineer- } \\
\text { ing work for } \\
\text { partial protection }\end{array}$ & $1.4 \%$ & $5 \%$ & $6.4 \%$ \\
\hline $\begin{array}{l}\text { The sum which if } \\
\text { invested in the } \\
\text { fund would give } \\
\text { total protection }\end{array}$ & & $0.7 \%$ & $5.2 \%$ \\
\hline
\end{tabular}

provision which when converted is the same as $5 \%$ of total cost.

In summary then for this structure see above.

While it is perhaps dangerous to generalise from such a broadly based argument as that outlined above, these figures do suggest that for this particular structural type better value might be obtained if more emphasis were placed on direct provisions for ductility with correspondingly reduced code loads. Also that from the national viewpoint better overall cover might be obtained if code base shears were reduced and the corresponding savings invested in a disaster fund.

\section{(iii) The Cost of going out of service:}

The cost of the structure going out of service is extremely small, does not affect the argument here and so has been omitted for clarity.

\subsection{A Medium Height Student Hostel Building:}

Like the previous example this structure also has a high potential risk to life; it is, however, a shear wall structure rather than the frame structure of the previous example and thus is useful to illustrate a different approach in assessing appropriate sums which might be spent on earthquake protection.

The building (illustrated in Figure 10 ) has a round form chosen by the architect for economy of internal circulation and of enclosing wall. The floors are flat plate and the external walls of minimum thickness reinforced concrete acting as shear walls. The higher tower, which is the one discussed here, has 12 main floors and two basements.

Such a structure (in contrast to a frame structure) can be given very little inherent ductility. As explained in paragraph 6.1 , it can only therefore meet the three objectives of earthquake engineering effectively by having a several hundred per cent increase in strength over that required by the code.

The tubular form of the outside shell is however extremely efficient for resisting lateral forces. Early calculations showed that if the tube wall thickness were chosen as the minimum for waterproofness and if extra reinforcing were added to fully utilise the shear strength of this concrete, the building could easily be made 2.4 times as strong as that required by the code. That is, it could be made to resist a base shear coefficient of 0.36 before passing out of the elastic range. Studies of cost showed this strength could be achieved for approximately $2.0 \%$ (of total building cost) above the cost of a structure designed to the code or $3.0 \%$ above a structure with just sufficient steel to be weatherproof.

These figures also include extra costs of certain partition detailing designed to reduce secondary or non-structural damage. These extra costs were judged by the client to be good value and were accepted.

To compare them now with the alternatives of investing in the fund :-

For the cost of life loss, take a $1 \%$ collapse risk as in the previous example and with a population of 180 the actual loss averaged over this type of building would be :-

$1 \% \times 180 \times 100,000 *=\$ 180,000 ;$

or on a total value of $\$ 720,000$ a loss ratio of $25 \%$. Figure Two then for a 40 year life gives $5 \frac{1}{2} \%$ for full cover for life protection。(by extrapolation)

As for the previous example, $0.7 \%$ is a maximum for full damage cover.

This gives a total of $6.2 \%$ as an upper limit for full cover in invested in the fund. This may be compared with the $3.0 \%$ quoted above for engineering provisions. As for the previous example, the cost of the structure going out of service is small and has been omitted for simplicity。

\subsection{A Railway Viaduct:}

This is a hypothetical example of a railway viaduct selected at a critical place on the North Island Main Trunk。 It has been chosen to demonstrate that for civil engineering works the cost of life loss is often negligible (very small risk of a passenger train on the bridge at the time of the earthquake), while on the other hand, the cost of the structure going out of service may be severe and thus justify a somewhat higher expenditure on engineering

* See comments on the evaluation of this figure in paragraph 7.2. 
provisions.

In a major shaking 20 miles of track might go out of commission, requiring about 4 weeks of full time emergency repair before trains can run again. If one major viaduct has lost several spans, it will take as much as 8 weeks to construct a temporary replacement.

If the earthquake occurs in a critical section of line such that rail traffic cannot be remrouted on alternative lines (there are such sections on the North Island Main Trunk), then 4 weeks of income loss for that section of the main trunk line must be charged to the bridge failure. Assuming this line income to be $\$ 500,000^{*}$ per week and assuming one-third of traffic can wait for the repair to be complete, one-third will be transhipped by road or sea (that is - on other agencies) and one-third is lost, then the direct loss to the N.Z. Railways for 4 weeks is $500,000 \times 2 / 3 \times 4$-i。e. \$1,333,000.

Add to this the cost of the temporary bridge, say, $\$ 250,000$, giving a total loss of $\$ 1,583,000$. If the capital value of the original viaduct is assumed at $\$ 500,000$ say, this gives a loss of $310 \%$. Now it is necessary to judge the loss ratio for bridges not specif ically designed for earthquake (i.e. what proportion might be expected to lose several spans*). From study of records at Niigata, Anchorage, Inangahua, etc., take a ratio of one in 4 as reasonable. This then gives a loss ratio of $\frac{310}{4}$ or $77 \%$, which, when applied to Figure 3

for a 60 year 1 ife shows that up to $18 \%$ may be spent on engineering provisions for preventing the bridge from going out of service before the equivalent sum which invested in the fund will give complete cover, is reached.

\subsection{Foundation Engineering for an Irrigation Barrage:}

One final example again to illustrate that for civil engineering works the cost of the facility going out of service can be a dominant factor.

Figure 11 illustrates the structure to be studied: it is a reinforced concrete barrage, one of an interlinked group which together form an important control system for the new and vast irrigation system in the upper tributaries of the river on the border between India and West Pakistan. The barrage was founded on a loose rine uniform sand (particle size almost entirely in the range 0.1 millimetres to 0.3 milimetres). Such a sand is subject to the risk of liquefaction in a major shaking (the area is seismically active at about the same level as New zealand) with the consequent risk of a general sliding failure of the entire structure. By means of a proprietary process known as Vibroflotation (in effect a very large poker-type vibrator as illustrated in Figure 12) the sand was densified effectively down to a depth of 25 feet below the structure. Figure 13 shows the increase in Raymond numbers achieved and demonstrates that the risk of liquefaction in a severe shaking has been effectively removed.

* Not a reliable rigure but approximately of the right order.
The question to be answered is:- apart 211 from any improvement achieved in general bearing capacity, was the cost of sand densification justified purely because of the reduced seismic risk?

It is assumed that :-

(i) The result of seismic liquefaction in the uncompacted sand would be a substantial lateral movement of the entire structure under the pressure of the retained water.

(ii) Damage to the facility itself when thi occurred would be not less than $50 \%$ of the capital value of the installation.

(iii) The structure would go out of service for a substantial time and because of the linked irrigation system, the losses are conservatively estimated at $200 \%$ of the cost of the barrage structure.

(iv) Just as every building is not necessarily damaged in a major shaking, every earthquake shaking need not cause liquefaction in every instance where uniform fine grained saturated sands occur. From general reading including the Ni-igata shaking, it is assumed that one failure in every five such barrages will be a conservative estimate。

(v) The topography and population downstream of the barrage is such that a major failure would not threaten human 1 if e。

Thus for damage the loss ratio is

$1 / 5 \times 50 \%=10 \%$ (from (ii) and (iv) above

and for going out of service the loss ratio is $1 / 5 \times 200 \%=40 \%$ (from (iii) and (iv) above

Applying these to Figures 2 and 3 for a 60 year 1 ife the sum of $12 \frac{1}{2} \%$ of initial capital cost is obtained as the fund contribution required to give total cover during an assumed 60 year 1 ife.

Now the capital cost of the barrage was $\$ 6,000,000$ approx. and of the Vibroflotation treatment $\$ 200,000$ or $3.3 \%$ of initial capital cost, thus it may be concluded the investment in Vibroflotation, if assessed solely as prevention of seisinic liquefaction, was well spent.

\subsection{Other examples:}

Numerous other exampleș, illustrating the losses consequent on a facility going out of service, could be found from the somewhat neglected field of earthquake protection of civil engineering works. For example, for the water supply system of a major city taken as a whole (i.e. to include reservoirs, reticulation, pumping stations, etc.) quite an appreciable sum can be justified for earthquake protection if the system can be maintained in effective use immediately after a serious shaking. This is because of the high consequent losses from fire if adequate high pressure water is not available. Yet in general, water supply engineeers tend to limit their earthquake engineering to the application of the New Zealand loading code to those few structures which might be part of the water supply system instead of studying the effectiveness of the system as a whole after a disaster. 
Sinilarly, in harbour engineering current ractice in New Zealand again tends to be circumscribed by the use of the New Zealand loading code static forces applied to individual structures. In fact the history of major earthluakes demonstrates that harbour works tend to be examples of catastrophic failures on a grand scale especially where deep loose fills are involved (such as those currently fashionable in some of New Zealand's major ports). A study of the loss of income (both for the port itself and for the nation) resulting from such a failure and using the methods outlined in this paper would show that those sums available for earthquake engineering should not be spent on structures which cannot hope to survive anyhow; rather they should be spent on ensuring that part of the port is free of such effects and is equipped with structures consciously designed to remain operative and thus to keep the port open at least for reduced traffic after a major shaking.

No doubt readers will be able to find many similar examples from their own experience。

\subsection{Conclusion:}

By setting up the concept of a hypothetical disaster fund this paper attempts to give engineers a yardstick which, with the addition of a large measure of engineering judgement, can be used to assess appropriate capital sums as upper Iimits for the earthquake engineering of major projects.

Because of the interest earning capacity of initial capital expenditure in the periods between major earthquakes, a striking feature of the analysis turns out to be the very small percentage of total capital which can be justified for earthquake engineering.

Though not the main thesis of this paper, the trend of some of the examples given suggests that as a matter of national interest, New Zealand might be better off if the severity of the seismic loading codes were relaxed (but with the addition of certain low cost provisions for ductility improvements) and if the money so saved were in fact invested in a real earthquake found outside New Zealand. But such a hypothesis would need closer study and further development of the ideas set out in this paper before it could have real status.

\subsection{Acknowledgements:}

The kind permission of those 1 isted below to publish the examples given is acknowledged.

Example 7.1 and 7.2 - Messrs. Wilkins \& Davies Construction Co. Ltd.

Example 7.3 - Messrs. Porter and Martin, Architects and Town Planners, Wellington。

Example 7.5 - The Cementation Co. Ltd., London and Messrs. Coode and Partners, Consulting Engineers, London。

\subsection{References:}

1. G. S. Beca and A. Tork, "Economic MultiStorey Building Structures for N.Z. Conditions." N.Z. Engineering Vol. 18 No. 3 March 1963.
2. J. Heyman, "Computers in Civil Enginoring", Institution of Civil Engineers Pruceeding Vol. 35 Qctober 1966.

3. J. R. Freeman, Earthquake Damage and Earthquake Insurance 1932.

4. J. P. Hollings, "Reinforced Concrete Seismic Design", Bulletin N.Z, Society for Earthquake Engineering, Vol. 2 No。 3 September 1969.

5. J. P. Hollings, "Rotational Capacity of a Reinforced Concrete Flat Slab to Column Connection." 'N.Z. Engineering' August 1967.

6. F.P.S. Lu, "Economic Decision-making for Engineers and Managers". 


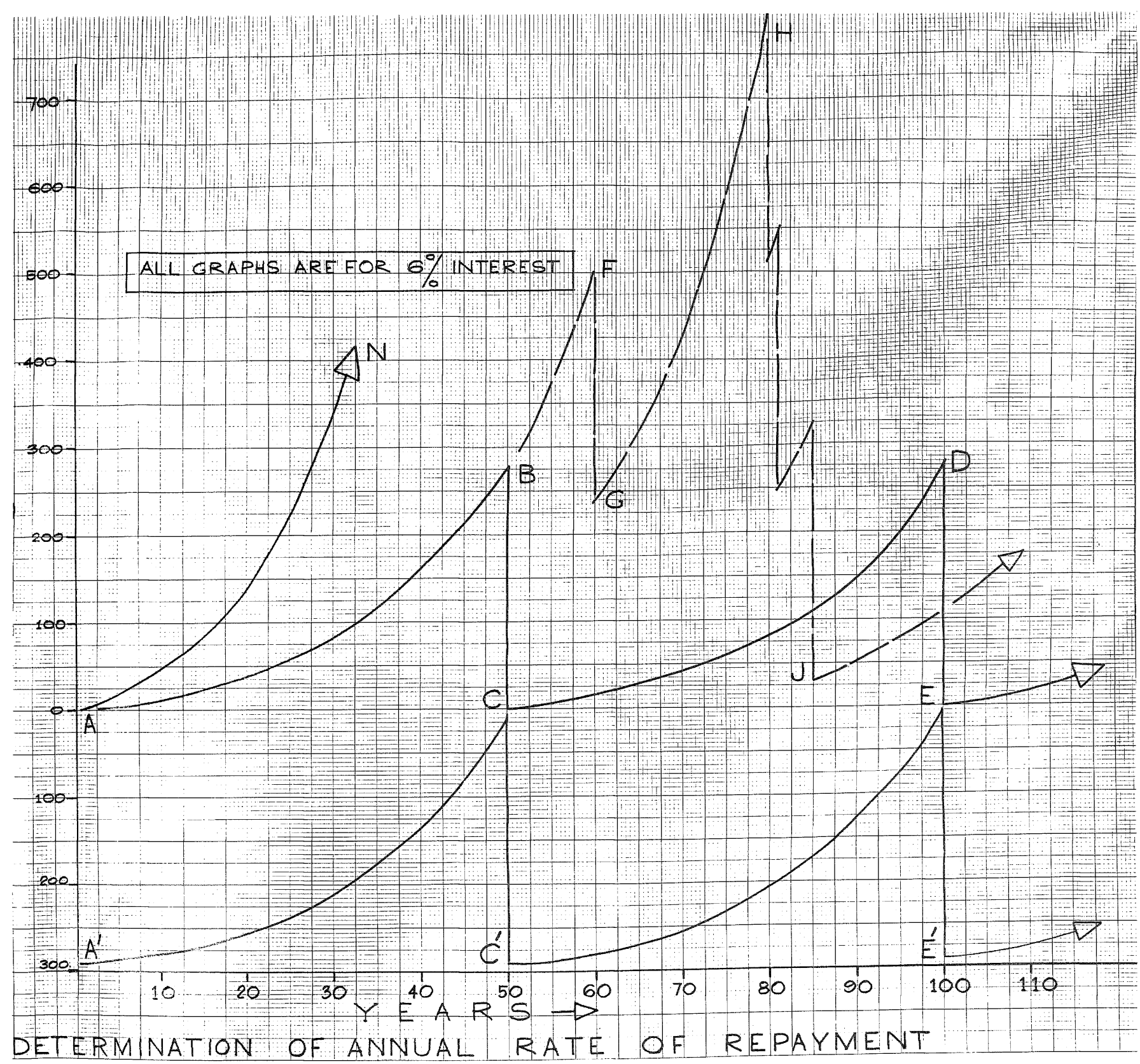




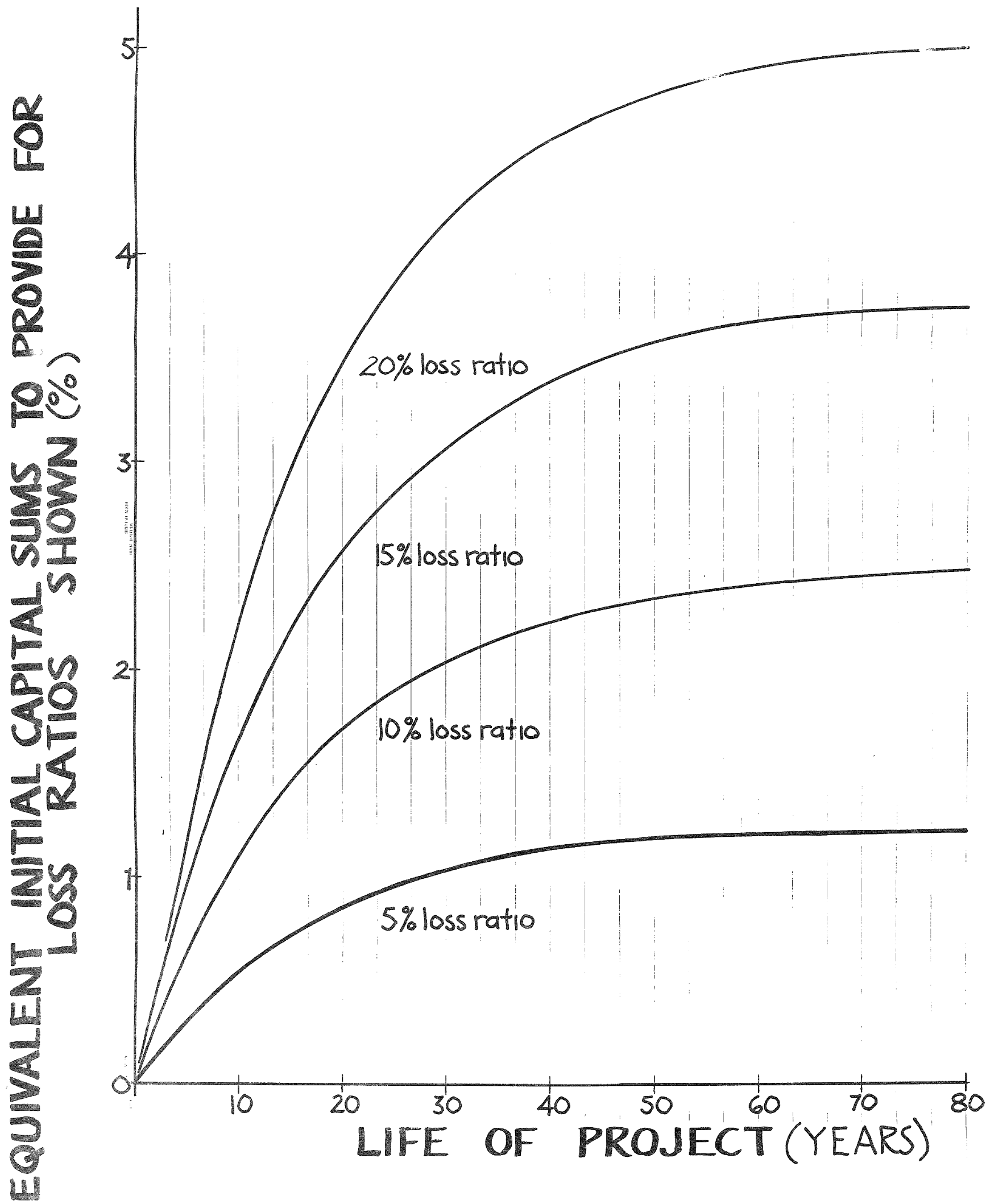

\section{INITIAL CAPITAL REQUIRED FOR VARIOUS LOSS RATIOS




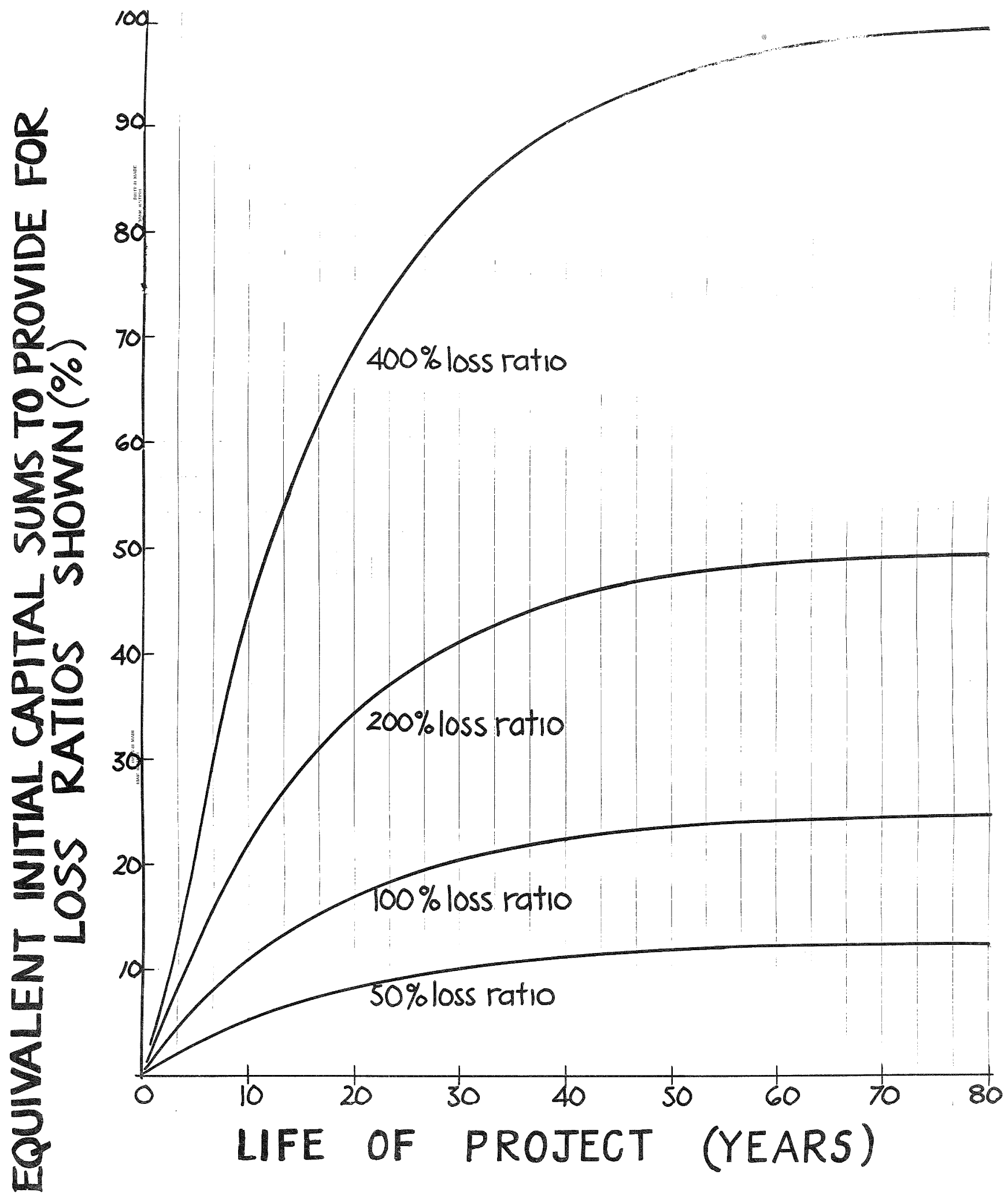

\section{INITIAL CAPITAL REQUIRED FOR VARIOUS LOSS RATIO}

Figure No. 3 


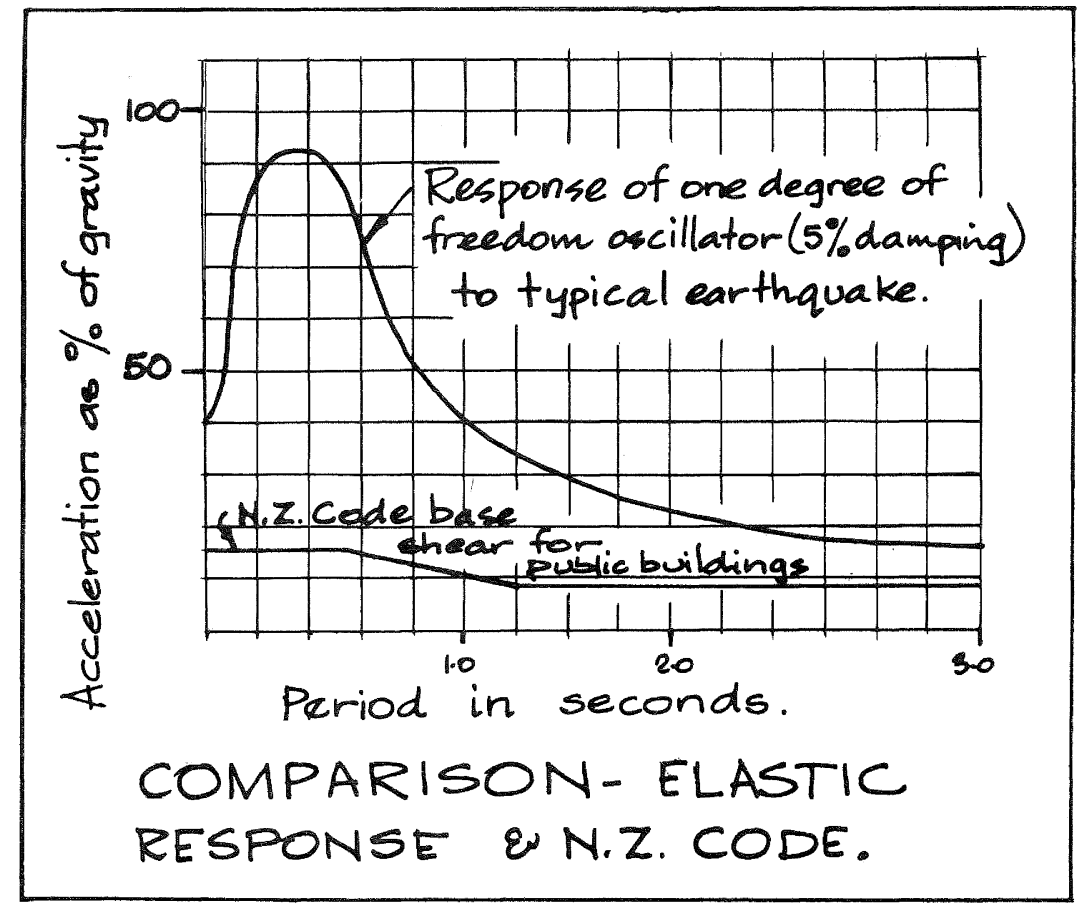

Figure 4

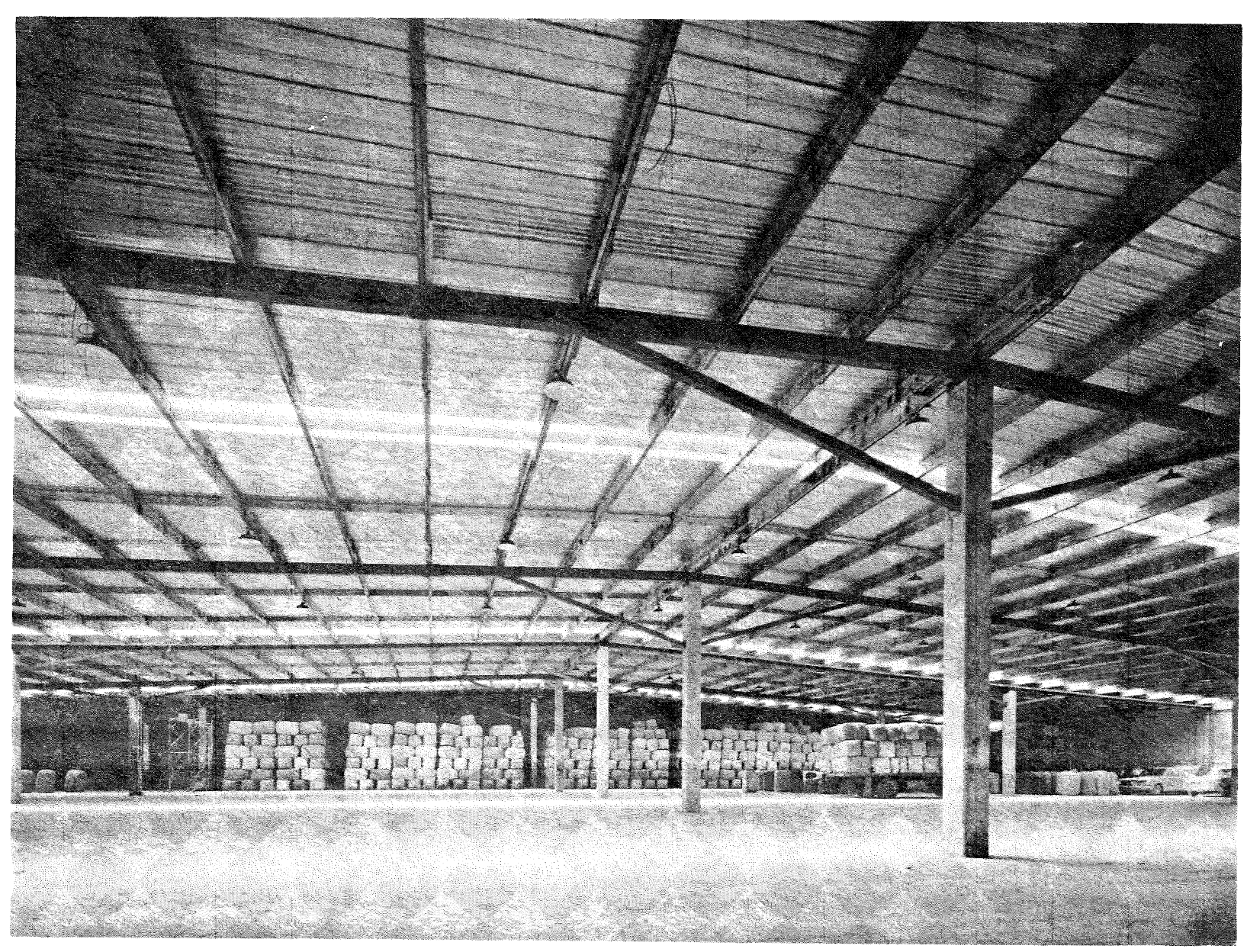

The Warehouse Building Described in example 7.1 Figure No. 5 


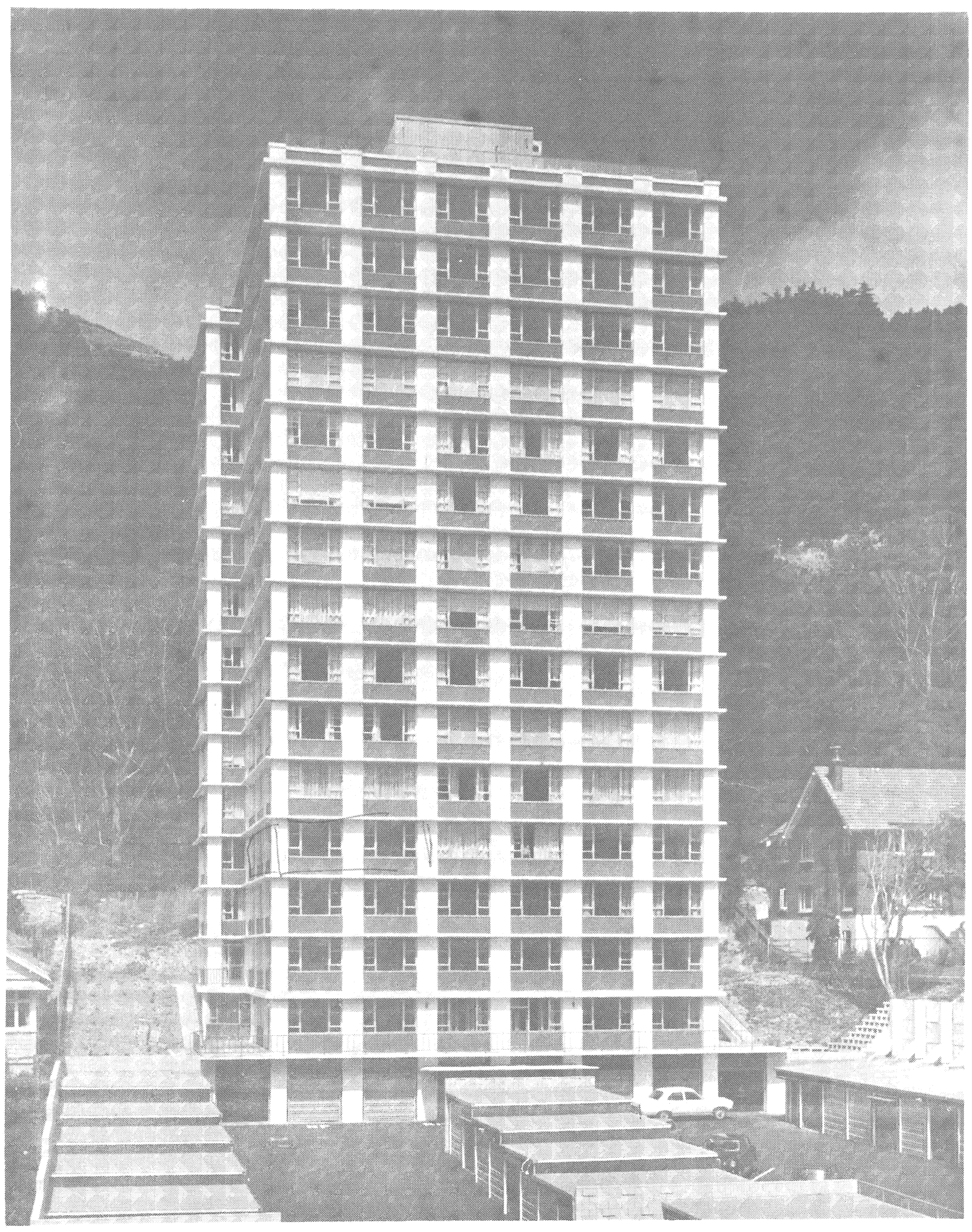

The High Rise Apartment Building of Example 7.2

Figure No. 6 


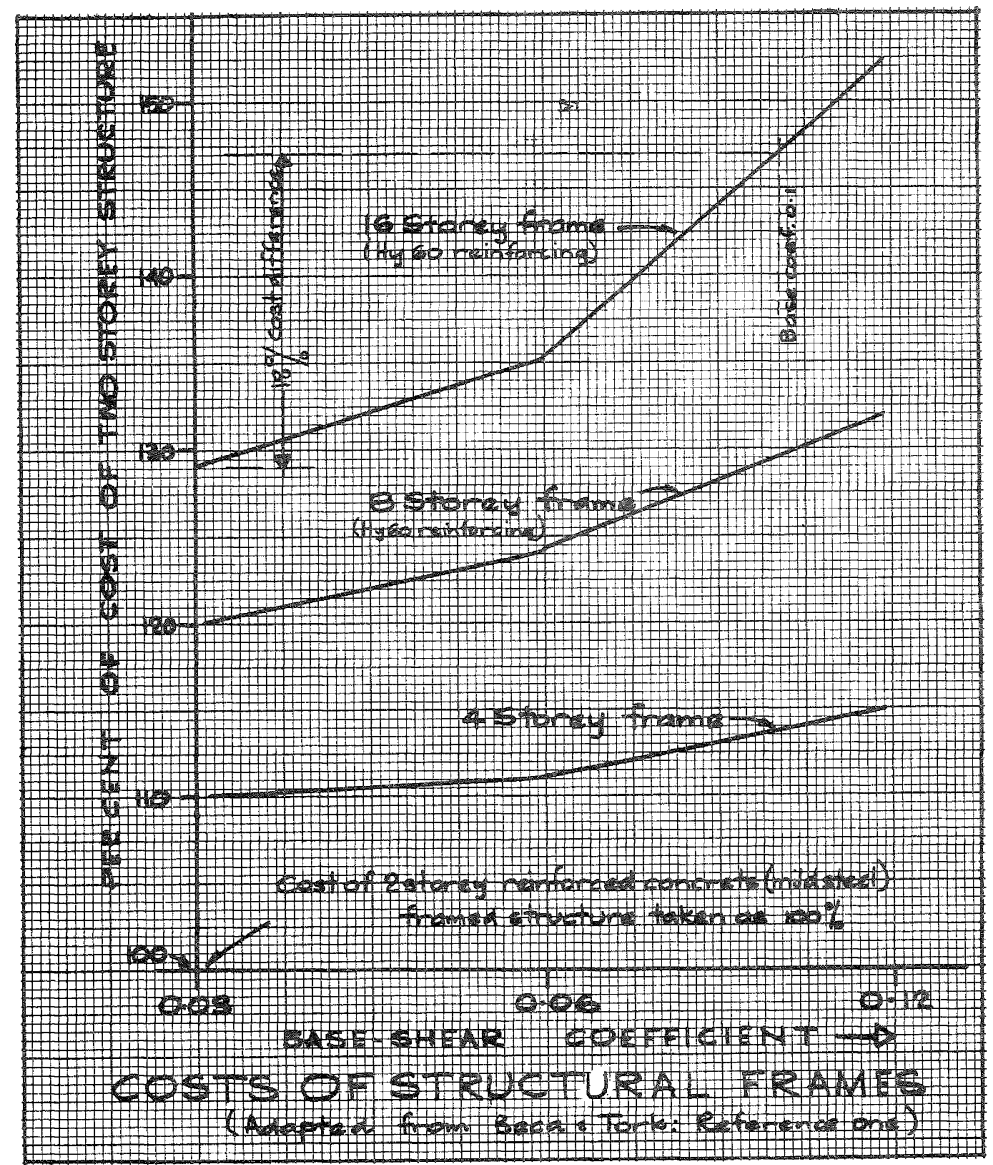

Figure 9

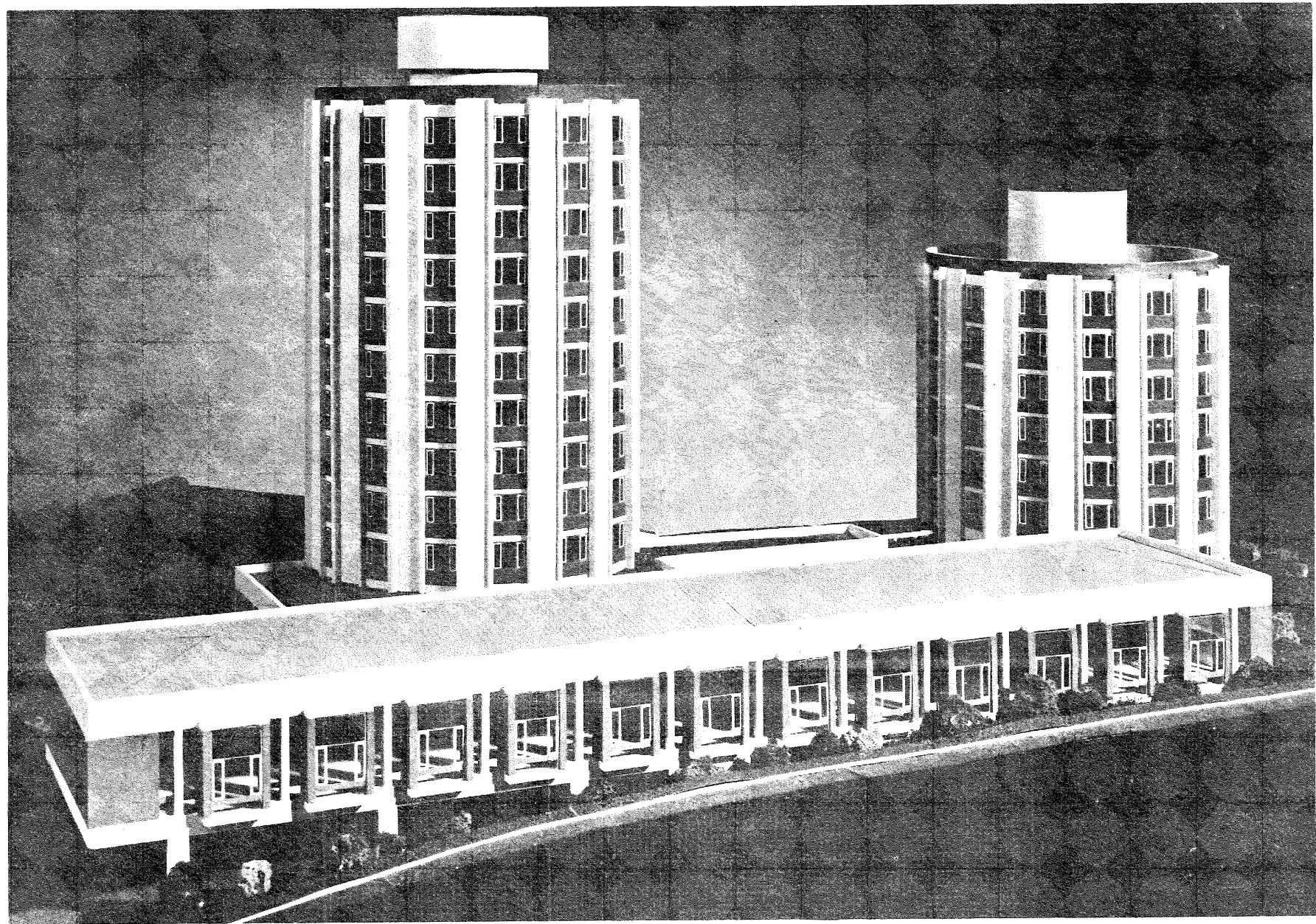

The Medium Height Student Hostel Building described in example 7.3

Figure No . 10 
농

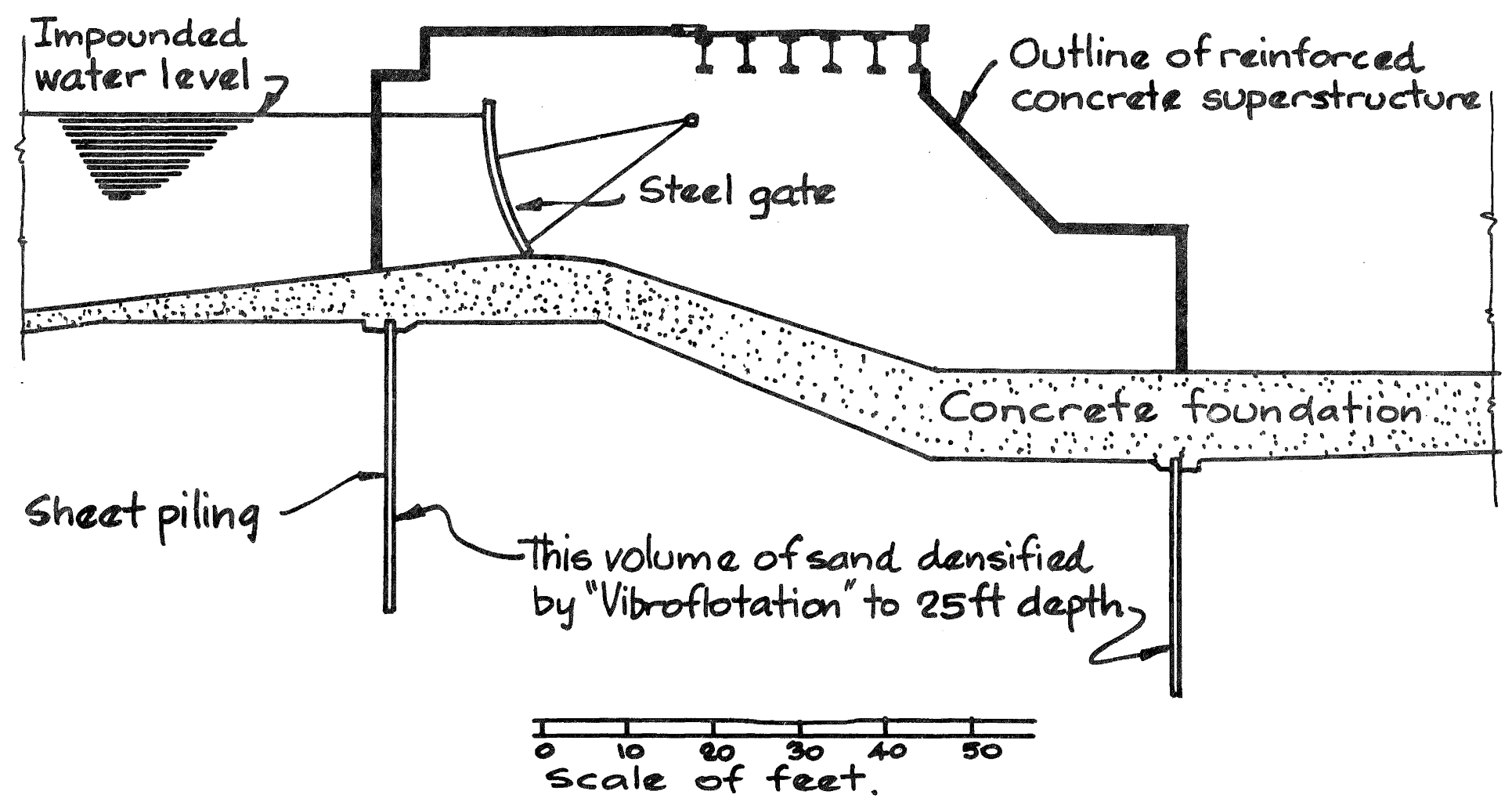

A CROSS-SECTION OF THE IRRIGATION BARRAGE OF EXAMPLE 7.5

FIGURE ELEVEN 


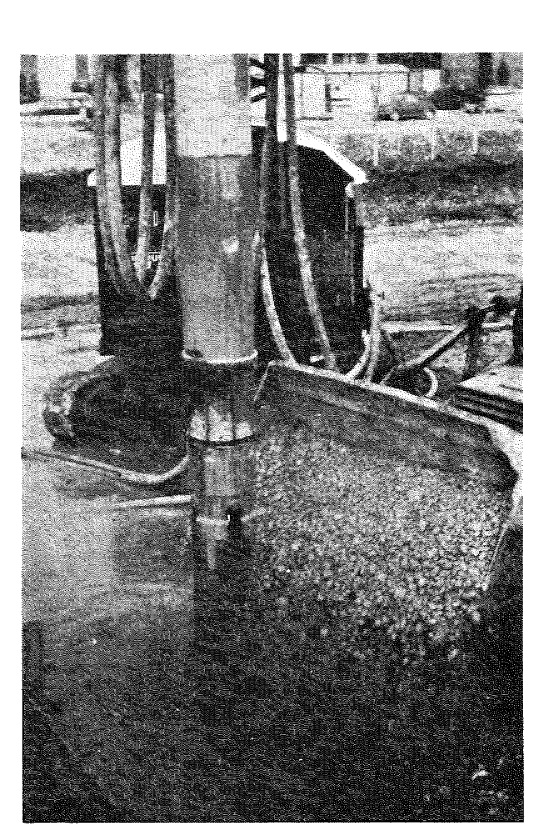

An example of the Vibroflotation Machine used for Compaction under the barrage of example 7.5

Figure No. 12

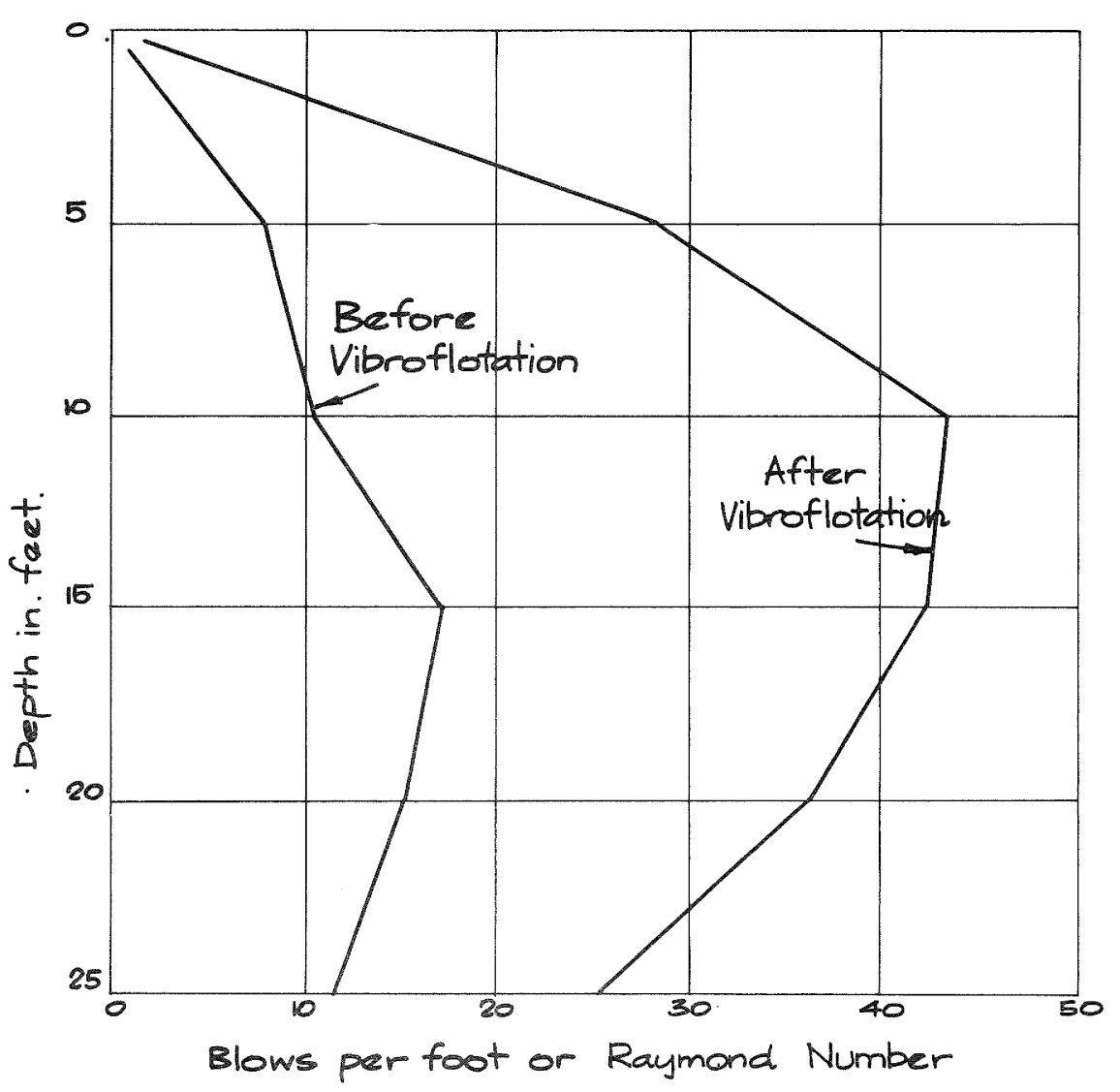

TYPICAL RAYMOND NUMBER IMPROVEMENT UNDER THE BARRAGE OBTAINED BY VIBROFLOTATION.

Refer example 7.5 